\title{
Combinatorial Theory of a Complete Graph $\mathbf{K}_{5}$
}

\author{
Geetha N. K. \\ Assistant Professor (S.G), \\ Department of Mathematics, Saveetha School of Engineering Saveetha University, Chennai, India
}

\begin{abstract}
For two given graphs $G$ and $H$, the Ramsey number $R(G, H)$ is the positive integer $N$ such that for every graph $F$ of order $N$, either $F$ contains $G$ as a subgraph. The Ramsey number $R\left(F_{1}, K_{4}\right)$ where $F_{1}$ is the graph of every triangle. The aim of this paper is to prove that $R\left(F_{l}, K_{n}\right)=2 I(n-1)+1$ for $n=4 \& I=3$ and $R\left(F_{l}\right.$, $\left.K_{n}\right)=2 I(n-1)+1$ for $I \geq n \geq 5$.
\end{abstract}

Keywords: Fan, Graph, Ramsey number, Tree, Wheel.

\section{Introduction}

A complete graph is a graph with an edge between every pair of vertices. A tree is a connected graph $\mathrm{T}$ that does not contain any cycles. The complete graph on $n$ vertices is denoted by $K_{n}$. The graph $\square$ is the compliment of $\mathrm{G}$ which is obtained from the complete graph on $|\mathrm{V}(\mathrm{G})|$ vertices by deleting the edges of $\mathrm{G}$. A graph $G$ is complete $p$ - particle if its vertices can be partitioned into $p$ non empty independent sets $V_{1}, V_{2} V_{3} V_{4}$ ....., $\mathrm{V}_{\mathrm{p}}$ such that its edge set $\mathrm{E}$ is formed by all edges that have one end vertex in $\mathrm{V}_{\mathrm{i}}$ and the other one in $V_{j}$ for $1 \leq i \leq j \leq p$. A complete 2-partite graph is called a complete $m$ by $n$ bipartite graph and denoted by $K_{m, n}$ if $\left|V_{1}\right|=m$ and $\left|V_{2}\right|=n$. A star $S_{n}$ is a complete 2-partite graph with independent sets $V_{1}=\{r\}$ and $V_{2}=n$. the vertex $r$ is called the root and the vertices in $V_{2}$ are called the leaves of $S_{n . .} A$ wheel $W_{m}$ is a graph on $m+1$ vertices obtained from a cycle on $\mathrm{m}$ vertices by adding a new vertex and edges joining it to all the vertices of the cycle $\left(\mathrm{W}_{\mathrm{m}}\right.$ is the join of $\mathrm{K}_{1}$ and $\mathrm{C}_{\mathrm{m}}$ ). A kipas $\square_{\mathrm{m}}$ is a graph on $\mathrm{m}+1$ vertices obtained from the join of $\mathrm{K}_{1}$ and $\mathrm{P}_{\mathrm{m}}$. A fan $\mathrm{F}_{\mathrm{m}}$ is a graph on $2 \mathrm{~m}+1$ vertices obtained from $\mathrm{m}$ disjoint triangles $\left(\mathrm{K}_{3} \mathrm{~s}\right)$ by identifying precisely one vertex of every triangle $\left(\mathrm{F}_{\mathrm{m}}\right.$ is the join of $\mathrm{K}_{1}$ and $\left.\mathrm{mK}_{2}\right)$.

Let $V(G)$ is the vertex set and $E(G)$ is the edge set for the graph $G=(V(G), E(G))$ and $\square$ is the compliment of G. G(S) denotes the subgraph for $S \leq V(G)$, induced by $S$ in $G$ and $G-S=G\left[V(G)-S\right.$ ]. $N_{s}(V)$ is the set of neighbours of vertex $V$ in $S$ and $d_{s}(V)=\left|N_{s}(V)\right|$. when $S=V(G)$, then $N_{v}=N_{G}(V), N_{[V]}=N_{(v)} U$ $\{V\}$ and $d(V)=d_{G}(V)$. let the graph of order $n$ is $k_{n}$ and $m_{k}$ is the union of $m$ vertex. $F_{\square}$ is the fan of order $(2 \square$ $+1)$ and the join of $k_{1}$ and $\square k_{2}$, which is $\square$ triangles sharing exactly one vertex. Where $k_{1}$ is the center of $F_{1}$. The Ramsey number $\mathrm{R}(\mathrm{F}, \mathrm{H})$ is the simplest integer for two given graphs $\mathrm{F}$ and $\mathrm{H}$ such that for any graph $\mathrm{G}$ of order $\mathrm{N}$, either the compliment of $\mathrm{G}$ contains $\mathrm{H}$ or $\mathrm{G}$ contains $\mathrm{F}$. Burr[1] formulated a lower bound for a connected graph $\mathrm{F}$ of the order $\mathrm{P}$, that is $\mathrm{R}(\mathrm{F}, \mathrm{H}) \geq(\mathrm{P}-1)(\mathrm{X}(\mathrm{H})-1)+\mathrm{S}(\mathrm{H})$, if $\mathrm{P} \geq \mathrm{S}(\mathrm{H})$, where $\mathrm{X}(\mathrm{H})$ is the chromatic number of $H$ and the minimum count of vertices in class under vertex coloring is $S(H)$ by $X(H)$ colors. Noting that $X\left(K_{n}\right)=n$ and $S\left(K_{n}\right)=1$ for the pair $F_{1}$ and $K_{n}$.

By Burr's lower bound, $R\left(F_{\square}, K_{n}\right) \geq 2 \square(n-1)+1$.For $n=3$, Gupta [2] showed that , $R\left(F_{\square}, K_{3}\right)=4 \square+1$ for $\square \geq 2$

For $n=4$, Surahmat [3] showed that , $\mathrm{R}\left(\mathrm{F}_{\square}, \mathrm{K}_{4}\right)=6 \square+1$ for $\square \geq 3$

The conjecture for $\mathrm{n}=5$ is to be confined in this paper.

G is a graph of order $8 \square+1, \square \geq 5$, let us show that $G$ contains an $F_{\square}$ or $\square$ contains $K_{5}$. let us assume that $G$ does not contain an $F_{\square}$ or $\square$ does not contains $K_{5}$. Let $\square € V(G)$, d(v) $\leq 2 \square-1$ then $G-N[v]$ is a graph of order at least $6 \square+1$ for $\square \geq 3, \square-\mathrm{N}[\mathrm{v}]$ contains a $\mathrm{k}_{4}$, it means that $\square$ contains a $\mathrm{k}_{5}$ which is a contradiction. If $\mathrm{d}[\mathrm{v}] \geq 2 \square+3$, then the maximum matching $\mathrm{M}$ of $\mathrm{G}[\mathrm{N}(\mathrm{v})]$ contains at least $\square$ edges for otherwise $\square[\mathrm{N}(\mathrm{v})-$ $\mathrm{V}(\mathrm{M})]$ will be a complete graph of order $\mathrm{S}$, which means that $\mathrm{G}$ has an $\mathrm{F}_{\square}$ which is-a contradiction. So , $2 \square \leq$ $\mathrm{d}(\mathrm{v}) \leq 2 \square+2$.

Let us assume $\mathrm{G}$ contains a sub graph $\mathrm{H}=\mathrm{K}_{2 \square-1}$. Let $\mathrm{V}_{0} \in \mathrm{V}(\mathrm{G})-\mathrm{V}(\mathrm{H})$ such that $\mathrm{d}_{\mathrm{H}}\left(\mathrm{V}_{0}\right)=\max \{$ $\left.\mathrm{d}_{\mathrm{H}}(\mathrm{v}) / \mathrm{V} € \mathrm{~V}(\mathrm{G})-\mathrm{V}(\mathrm{H})\right\}$. Then $\mathrm{G}-\left(\mathrm{V}(\mathrm{H}) \mathrm{U}\left\{\mathrm{V}_{0}\right\}\right)$ is a graph of order $6 \square+1$.

As $\square$ has no $\mathrm{K}_{5}$

$\mathrm{V}(\mathrm{H}) \mathrm{U}\left\{\mathrm{V}_{0}\right\} \leq \mathrm{U}_{\mathrm{i}=1}^{4} \mathrm{~N}\left(\mathrm{U}_{\mathrm{i}}\right)$

It means that $\max \left\{\mathrm{d}_{\mathrm{H}}\left(\mathrm{V}_{\mathrm{i}}\right) / 1 \leq \mathrm{i} \leq 4\right\} \geq[(2 \square-1) / 4] \geq 3$.

If $\mathrm{d}_{\mathrm{H}}\left(\mathrm{V}_{0}\right) \geq 4$, the $\mathrm{V}_{\mathrm{i}}$ has two adjacent values in $\mathrm{N}_{\mathrm{H}}\left(\mathrm{V}_{0}\right) \mathrm{U}\left\{\mathrm{V}_{0}\right\}$, 
If $\mathrm{d}_{\mathrm{H}}\left(\mathrm{V}_{0}\right)=3$, then $\mathrm{d}_{\mathrm{H}}\left(\mathrm{V}_{\mathrm{i}}\right) \leq \mathrm{d}_{\mathrm{H}}\left(\mathrm{V}_{0}\right)=3$ for $1 \leq \mathrm{i} \leq 4$, which means that $\mathrm{d}_{\mathrm{H}}\left(\mathrm{V}_{\mathrm{i}}\right) \geq 2$ and $\mathrm{N}_{\mathrm{H}}\left(\mathrm{V}_{\mathrm{i}}\right) \cap \mathrm{N}_{\mathrm{H}}\left(\mathrm{V}_{0}\right) \neq \phi$. In either cases, $G\left[V(H) U\left\{V_{0}, V_{i}\right\}\right]$ contains an $F_{\square}$, a contradiction. So $G$ does not contain $K_{2 \square-1}$.

For $1 \leq \mathrm{i} \leq 4$, set $\mathrm{X}_{\mathrm{i}}=\left\{\mathrm{V} / \mathrm{d}_{\mathrm{v}}(\mathrm{v})=\mathrm{I}, \mathrm{V} \in \mathrm{V}(\mathrm{G})\right\}$

$\sum_{\mathrm{i}=1}^{4}\left|\mathrm{X}_{\mathrm{i}}\right|=8 \square-3$

$\sum_{i=1}^{4} \mathrm{i}\left|\mathrm{X}_{\mathrm{i}}\right|=\sum_{\mathrm{i}=1}^{4} \mathrm{~d}\left(\mathrm{U}_{\mathrm{i}}\right)$

$\left|X_{i}\right| \geq 8 \square-14+\left|X_{3}\right|+2\left|X_{4}\right| \geq 8 \square-14$.

$\mathrm{X}_{1 \mathrm{i}}=\mathrm{N}_{\mathrm{X} 1}\left(\mathrm{~V}_{\mathrm{i}}\right), 1 \leq \mathrm{i} \leq 4$

As $\square$ has no $\mathrm{K}_{5}, \mathrm{G}\left[\mathrm{X}_{1 \mathrm{i}} \mathrm{U}\left\{\mathrm{U}_{\mathrm{i}}\right\}\right]$ is a complete graph.

And as $G$ has no $K_{2 \square-1},\left|X_{1 i} U\left\{U_{i}\right\}\right| \leq 2 \square-2$ which means $\left|X_{1 i}\right| \leq 2 \square-3$ for $1 \leq \mathrm{i} \leq 4$.

Hence $\left|\mathrm{X}_{1 \mathrm{i}}\right|=\sum_{\mathrm{i}=1}^{4}\left|\mathrm{X}_{\mathrm{i}}\right|=8 \square-12$ and $\left|\mathrm{X}_{3}\right|+2\left|\mathrm{X}_{4}\right| \leq 2$

So $\left|\mathrm{X}_{2}\right| \geq 7$.

As $G$ contains no $K_{2 \square-1}, U_{i}-N_{(y)} \neq \phi$. Then $G\left[U_{i} U U_{j}-N_{(y)}\right]$ is a complete graph.

$G$ has no $F_{\square}, V_{i}$ and $U_{j}$ are complete graphs. And $d_{u j}(U) \leq 3$ for any $U € V_{i}$, Such that $\left|V_{j}\right| \geq 2 \square-4$ and $\square \geq 5 . \mathrm{dV}_{\mathrm{j}}(\mathrm{y}) \geq\left|\mathrm{U}_{\mathrm{j}}\right|,\left|\mathrm{U}_{\mathrm{j}}-\mathrm{N}_{(\mathrm{y})}\right| \geq(2 \square-4)-3 \geq 3$.

Where $\mathrm{U}_{\mathrm{j}}$ is pair wise vertex-disjoint.

If $\left|\mathrm{U}_{4}\right|=2 \square-2$, then, $\mathrm{X}_{2}=\mathrm{U}_{1} \leq \mathrm{i} \leq \mathrm{j} \leq 4$ and $\mathrm{Y}_{\mathrm{ij}}=\phi$ which contradicts $\left|\mathrm{X}_{2}\right| \geq 7$.

So, $2 \square-4 \leq\left|\mathrm{U}_{4}\right| \leq 2 \square-3$.

$\left|\mathrm{U}_{3}\right|+\left|\mathrm{U}_{4}\right| \geq 4 \square-6$ and $\left|\mathrm{U}_{4}\right| \leq 2 \square-3$

$\sum_{\mathrm{i}=1}^{4} \mathrm{~d}\left(\mathrm{U}_{\mathrm{i}}\right)=8 \square+8, \mathrm{~d}_{\mathrm{X} 2}\left(\mathrm{U}_{4}\right)=6$

Assume $\mathrm{N}_{\mathrm{x} 2}\left(\mathrm{U}_{4}\right)=\left\{\mathrm{y}_{\mathrm{i}} / 1 \leq \mathrm{i} \leq 6\right\}$ and $\square$ contains no $\mathrm{K}_{5}, \mathrm{G}\left\{\mathrm{N}_{\mathrm{X} 2}\left(\mathrm{U}_{4}\right)\right\}$ contains at least one edge.

$\mathrm{Y}_{1}, \mathrm{Y}_{2} € \mathrm{E}(\mathrm{G})$

And as $G$ has no $F_{\square}, G\left[\left\{y_{3}, y_{4}, y_{5}, y_{6}\right\}\right]$ contains no edge. As $\square$ has no $K_{5}{ }^{\prime}$

$\left|\left\{\mathrm{y}_{3}, \mathrm{y}_{4}, \mathrm{y}_{5}, \mathrm{y}_{6}\right\} \cap\left(\mathrm{N}\left(\mathrm{U}_{1}\right) \mathrm{UN}\left(\mathrm{U}_{2}\right)\right)\right| \geq 2$

Let us assume $\left\{\mathrm{y}_{3}, \mathrm{y}_{4}\right\} \leq \mathrm{N}\left(\mathrm{U}_{1}\right) \mathrm{U} \mathrm{N}\left(\mathrm{U}_{2}\right)$

$\mathrm{dU}_{4}\left(\mathrm{y}_{3}\right) \geq 3$ and $\mathrm{dU}_{4}\left(\mathrm{y}_{4}\right) \geq 3$,

which means that $d_{x 14}\left(y_{3}\right) \geq 2$ and $d_{x 14}\left(y_{4}\right) \geq 2$

This shows that there exists $U^{\prime}$ and $U € X_{14}$ such that $U^{\prime} y_{3}, U^{\prime \prime} y_{4} € E(G)$ and shows that G[ $U_{4} U\left\{y_{1} y_{2}\right.$ $\left.\left.\mathrm{y}_{3} \mathrm{y}_{4}\right\}\right]$ has an $\mathrm{F}_{\square}$ having $\mathrm{U}_{4}$ as center, which is a contradiction.

This proves that $\mathrm{R}\left(\mathrm{F}_{\square}, \mathrm{K}_{5}\right)=8 \square+1$ for $\square \geq 5$.

\section{References}

[1] S.A. Burr, Ramsey numbers involving graphs with long suspended paths, Journal of London Mathematical Society 24 (1981), $405-$ 413.

[2] S.K. Gupta, L. Gupta and A. Sudan, On Ramsey numbers for fan-fan graphs, Journal of Combinatorics, Information \& System Sciences 22 (1997), 85-93.

[3] Surahmat, E.T. Baskoro and H.J. Broersma, The Ramsey numbers of fans versus K4, Bulletin of the Institute of Combinatorics and its Applications 43 (2005), 96-102. 
[4] S.P. Radziszowski, Small Ramsey numbers, The Electronic Journal of Combinatorics, (2011), DS1.13.

[5] Yanbo Zhang, Yaojun Chen, The Ramsey numbers of fans versus a complete graph of order five , Electronic journal of graph theory and Applications 2 (1) (2014), 66-69.

[6] D. Li, H. Lai, M. Zhan, Eulerian subgraphs and Hamilton-connected line graphs, Discrete Appl. Math. 145 (2005), 422-428.

[7] H. Fleischner, The square of every two-connected graph is hamiltonian, J. Combin. Theory Ser. B 16 (1974), 29-34.

[8] B. Li, H.J. Broersma and S. Zhang, Pairs of forbidden induced subgraphs for homogeneously traceable graphs, Discrete Math. 312 (2012), 2800-2818.

[9] M. Miller and J. Sir'an, Moore graphs and beyond: A survey of the degree/diameter problem, Electron. J. Combin. 20(2) (2013), DS14v2.

[10] P. Morillo, M.A. Fiol, J. F abrega, The diameter of directed graphs associated to plane tesselations, Ars Combin. 20A(4) (1985), $17-27$.

[11] J.L.A. Yebra, M.A. Fiol, P. Morillo, and I. Alegre, The diameter of undirected graphs associated to plane tesselations, Ars Combin. 20B(4) (1985), 159-171. 